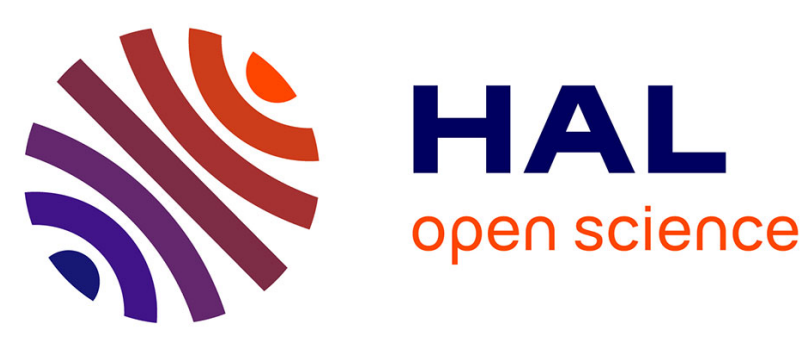

\title{
Millington Effect and Propagation Enhancement in 60-GHz Body Area Networks
}

Theodoros Mavridis, Carole Leduc, Luca Petrillo, Julien Sarrazin, Maxim

Zhadobov, Ronan Sauleau, Aziz Benlarbi-Delai, Philippe de Doncker

\section{- To cite this version:}

Theodoros Mavridis, Carole Leduc, Luca Petrillo, Julien Sarrazin, Maxim Zhadobov, et al.. Millington Effect and Propagation Enhancement in $60-\mathrm{GHz}$ Body Area Networks. IEEE Transactions on Antennas and Propagation, 2016, 64 (2), pp.776-781. 10.1109/TAP.2015.2505741 . hal-01249928

\section{HAL Id: hal-01249928 \\ https://hal.sorbonne-universite.fr/hal-01249928}

Submitted on 4 Jan 2016

HAL is a multi-disciplinary open access archive for the deposit and dissemination of scientific research documents, whether they are published or not. The documents may come from teaching and research institutions in France or abroad, or from public or private research centers.
L'archive ouverte pluridisciplinaire HAL, est destinée au dépôt et à la diffusion de documents scientifiques de niveau recherche, publiés ou non, émanant des établissements d'enseignement et de recherche français ou étrangers, des laboratoires publics ou privés. 


\section{Millington Effect and Propagation Enhancement in 60-GHz Body Area Networks}

\author{
Theodoros Mavridis, Carole Leduc, Luca Petrillo, Julien \\ Sarrazin, Maxim Zhadobov, Ronan Sauleau, Aziz \\ Benlarbi-Delaï, Philippe De Doncker
}

\begin{abstract}
Millington effect for on-body propagation enhancement is presented in the $60-\mathrm{GHz}$ band. Millington's equations are developed to describe propagation above a flat inhomogeneous surface. This study focuses on mixed paths (human skin metallic) for on-body scenarios. It is shown that adding metallic paths on the human skin can improve the power link budget between two nodes placed on the body. Two different schemes are studied experimentally to assess the analytical model using a flat phantom with electric properties of human skin and different lengths of metallic inserts. The first scheme considers a metallic plate between the transmitting and receiving antennas, while the second scheme proposes locating the metallic plates under the antennas. It is shown that the second scheme yields a better link budget than the first one for the same length of metal. Moreover, a numerical study is performed to assess the impact of the following different parameters: the location of the metal plate, size of the plate and the height of the antennas. Excellent agreement between numerical and experimental results has been shown. In the best cases, the presented techniques allow to improve the path loss of 10 to $20 \mathrm{~dB}$.
\end{abstract}

Index Terms-Body Area Networks, Millimeter waves, $60 \mathrm{GHz}$, On-Body, Enhancement, Millington, Norton

\section{INTRODUCTION}

Body Area Networks (BANs) studies have been mainly carried out in the 2.4-GHz band and for ultra-wideband applications [1], [2]. Operating at higher frequencies, especially at millimeter waves, offers several key advantages including smaller devices and increased data rates. In this frame, various studies on the antenna design and propagation models have been reported for BAN applications in the $60-\mathrm{GHz}$ band.

In particular, analytical and numerical models have been proposed recently to model on-body propagation at $60 \mathrm{GHz}$. The small skin depth, about $0.5 \mathrm{~mm}$ for the human body [3], allows one to consider a body model with only one layer for propagation studies [4]. The main on-body propagation features have been studied in [5] using a flat body model and Nortons equations. It has been shown that the path loss exponent is about 3.4 for vertical polarization and about 4 for horizontal polarization. These values have been experimentally verified on a flat skin-equivalent phantom. Cylindrical body models have been also considered to study propagation of creeping waves [6]. It has been shown that the received power in $\mathrm{dB}$ follows a linear decay with distance. For a cylinder

T. Mavridis, L. Petrillo and P. De Doncker are with OPERA Dpt. Wireless Communications Group, Université Libre de Bruxelles (ULB), B1050 Brussels, Belgium e-mail: (tmavridi@ulb.ac.be ; lpetrillo@ulb.ac.be ; pdedonck@ulb.ac.be)

T. Mavridis, J. Sarrazin and A. Benlarbi-Delaï are with Sorbonne Universits, UPMC Univ Paris 06, UR2, L2E, F-75005, Paris, France, France e-mail: (julien.sarrazin@upmc.fr; aziz.benlarbi_delai@umpc.fr)

C. Leduc, M. Zhadobov and R. Sauleau are with the Institute of Electronics and Telecommunications of Rennes (IETR), UMR CNRS 6164, University of Rennes 1, 35042 Rennes, France radius from 0.2 to $0.1 \mathrm{~m}$, attenuation is about 3 to $4 \mathrm{~dB} / \mathrm{cm}$ for the vertical polarization and from 4 to $6 \mathrm{~dB} / \mathrm{cm}$ for the horizontal polarization.

These two models lead to different estimations for the received power depending on the chosen geometry. The first one is valid for line-of-sight scenarios while the second one has been developed for non-line-of-sight communications. These models are very attractive to define lower and upper bounds for the received power, and can also be used to study the impact clothes on propagation (Ref. [7] shows that regular textiles have a negligible effect on the path loss exponent). Also, in [8] and in [9], dynamic models based on measurements have been proposed. It has been shown that the body shadowing creates supplementary propagation losses. This high propagation loss is a critical issue for on-body communication systems, and recent studies have been proposed to tackle this problem. A more favorable path loss has been measured in [8] by putting the nodes at larger distances from the body (1 or $2 \mathrm{~cm}$ ). In [10], an electro textile covering the skin between the transmitter and receiver is used to improve the wave propagation along human body.

In this paper, we propose a more realistic scenario in which only some body parts are covered with an electro textile or metallic inserts. Millington equations are used to analytically investigate this problem. Propagation above mixed propagation paths has been solved using a combination of Norton's equation [11] by G. Millington [12], [13] to study propagation above an assumed flat sea taking into account the presence of islands. We propose here to use the Millington equations for $60-\mathrm{GHz}$ BANs. Since it has been shown in [10] that path loss above a lossy dielectric surface is higher than above a conducting surface, we propose to create artificially mixed paths composed of skin and metallic sheets, with the aim to increase the link budget without covering all surfaces with a metallic layer.

This paper is organized as follows. Section II describes the propagation model and analytical formulation used to study the Millington's effect and the Norton's surface wave. An experimental validation of the proposed analytical formulation is proposed in Section III. Numerical simulations are used in Section IV to provide accurate design guide lines. Conclusions are drawn in Section V.

\section{ANALYTiCAl Model}

\section{A. Geometry under study}

The human body is assumed to be a flat lossy half space in free space. As presented in Fig. 1, the flat surface modelling the human body is split into $N$ homogeneous regions, where $d_{i}$ denotes the length of $i^{\text {th }}$ region in the propagation direction $\hat{x}$. The relative complex permittivity of each dielectric region is given by $\varepsilon_{i}^{c}=\varepsilon_{i}-j \sigma / \omega \varepsilon_{0}$, with $\varepsilon_{i}$ the real relative permittivity and $\sigma_{i}$ the conductivity of $i^{\text {th }}$ segment. All regions are assumed to be non-magnetic (permeability $\left.\mu_{0}\right)$. The source and observation points are vertically-polarized elementary dipoles with current $I$ and equivalent height $l$. Hence, only the $z$-component (normal to the surface) of the electric field is considered in the following since it has been 


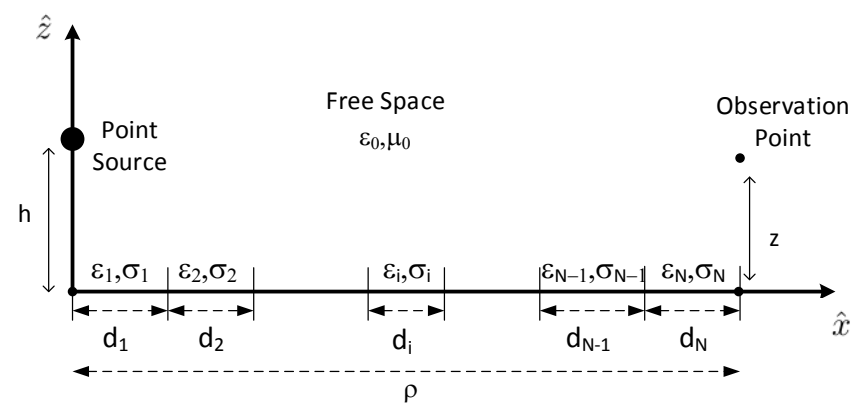

Fig. 1. Millington scheme geometry. The flat surface is split up into $\mathrm{N}$ segments with different electrical properties. The propagation between the point source and the observation point is studied.

shown in [5], [14] that the vertical polarization is dominant in on-body propagation and that the $x$ - and $y$-component of the electric field are negligible with respect to the $z$ component. The source dipole and the observation point are placed along $\hat{z}$ at heights $h$ and $z$ above the body surface, respectively. In the following, a special focus is given to 3segment surfaces. These segments are assumed to be either human skin or metallic inserts. In all experiments, aluminium inserts of $100 \mu \mathrm{m}$ with a conductivity $\sigma=37 \times 10^{6} \mathrm{~S} / \mathrm{m}$ have been used. The human skin is assumed to have a real relative permittivity of $\varepsilon=7.98$ and a conductivity $\sigma=36.4 \mathrm{~S} / \mathrm{m}$ [15].

\section{B. Norton Equations}

Since Millington's formulation assumes propagation over a set of homogeneous surfaces, Norton's equations should be used as a prerequisite. They are summarized below for the sake of consistency. Temporal dependence is assumed to be $e^{j \omega t}$ and is then removed. The solution provided in [10] is given here for vertical polarization and only the $z$-component of the electric field is considered.

$$
\begin{aligned}
& E_{z}(\rho, z)=\frac{2 \omega \mu_{0} I l}{4 \pi k_{0}} \\
& \times\left\{e^{j k_{0} r_{1}}\left[\frac{j k_{0}}{r_{1}}-\frac{1}{r_{1}^{2}}-\frac{j}{k_{0} r_{1}^{3}}-\left(\frac{z-h}{r_{1}}\right)^{2}\left(\frac{j k_{0}}{r_{1}}-\frac{3}{r_{1}^{2}}-\frac{3 j}{k_{0} r_{1}^{3}}\right)\right]\right. \\
& +e^{j k_{0} r_{2}}\left[\frac{j k_{0}}{r_{2}}-\frac{1}{r_{2}^{2}}-\frac{j}{k_{0} r_{2}^{3}}-\left(\frac{z+h}{r_{2}}\right)^{2}\left(\frac{j k_{0}}{r_{2}}-\frac{3}{r_{2}^{2}}-\frac{3 j}{k_{0} r_{2}^{3}}\right)\right] \\
& \left.-2 k_{0}^{2} / \sqrt{\varepsilon_{c}} e^{j k_{0} r_{2}}\left(\frac{\pi}{k_{0} r_{2}}\right)^{1 / 2}\left(\frac{\rho}{r_{2}}\right) e^{-j w} F(w)\right\}
\end{aligned}
$$

where $r_{1}=\sqrt{\rho^{2}+(z-h)^{2}}, r_{2}=\sqrt{\rho^{2}+(z+h)^{2}}$ and

$$
\begin{array}{r}
F(w)=\frac{1}{2}(1+j)-\int_{0}^{w} \frac{e^{j t}}{(2 \pi t)^{1 / 2}} d t, \\
w=\frac{k_{0} r_{2}}{2}\left(\frac{r_{2} / \sqrt{\varepsilon_{c}}+z+h}{\rho}\right)^{2} .
\end{array}
$$

Norton's equation (1) is evaluated at $60 \mathrm{GHz}$ in Fig. 2 for human skin and metallic surfaces with $I \times l=1$ A.m and for $h=z=3 \mathrm{~mm}$. It can be inferred, as in [5], [10], that the path loss exponent is equal to 2 and 4 , for propagation over perfect electrical conductor (metal) and skin surface respectively. This property will be used in the following to enhance propagation

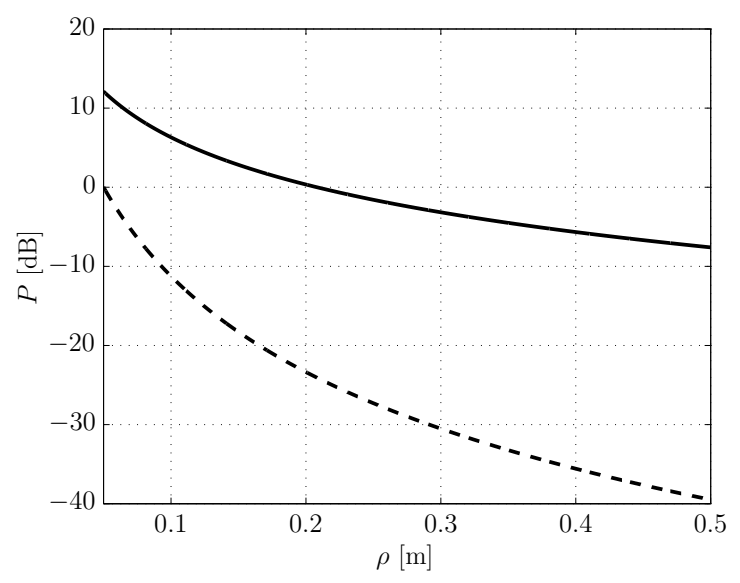

Fig. 2. Power $P=20 \log _{10}\left|E_{z}\right|$ on a flat surface. Comparison between metallic and skin surfaces. The curves have been normalized to have a $0-\mathrm{dB}$ for path loss over skin surface at $5 \mathrm{~cm}$ distance from the point source.

over the body using small-size metallic inserts, as described by Millington.

\section{Millington Effect}

Millington [12] discovered for the first time signal attenuation and recovery at sea-land transitions in the HF band. He introduced a generic approach to determine the power level above an inhomogeneous surface: the recursive equations of the Millington Curve Fitting Method (equations (3) to (7), which is the most accurate available and satisfies the reciprocity condition [16]. These equations are reminded here for the sake of completeness. Millington [12] developed the following method by empirically correcting the non-reciprocity of Norton's equations above in the case of mixed groundwave paths. He proposed to calculate the direct and reversed powers $P^{\mathrm{D}}$ and $P^{\mathrm{R}}$ (in $\mathrm{dB}$ ) as follows

$$
\begin{gathered}
P^{\mathrm{D}}=\sum_{i=1}^{N} P_{i}\left(s_{i}\right)-\sum_{i=2}^{N} P_{i}\left(s_{i-1}\right) \\
P^{\mathrm{R}}=\sum_{i=1}^{N} P_{i}\left(r_{i}\right)-\sum_{i=2}^{N} P_{i-1}\left(r_{i}\right) \\
s_{i}=\sum_{n=1}^{i} d_{n} \\
r_{i}=\sum_{n=1}^{i} d_{N-n+1}
\end{gathered}
$$

The total field strength $P_{\text {tot }}$ is then given by

$$
P_{\text {tot }}=\frac{1}{2}\left(P^{\mathrm{D}}+P^{\mathrm{R}}\right)
$$

In these equations, $P_{i}(x)$ is the power in $\mathrm{dB}$ at the homogeneous $i^{\text {th }}$ segment at distance $x$ and it can be noted that the distance $\rho=\sum_{n=1}^{N} d_{n}$. If a 3-path scenario is considered, it can be written that

$$
\begin{aligned}
P^{\mathrm{D}}= & P_{1}\left(d_{1}\right)-P_{2}\left(d_{1}\right)+P_{2}\left(d_{1}+d_{2}\right) \\
& -P_{3}\left(d_{1}+d_{2}\right)+P_{3}\left(d_{1}+d_{2}+d_{3}\right)
\end{aligned}
$$


and the reversed field strength $P_{r}$ as

$$
\begin{aligned}
P^{\mathrm{R}}= & P_{3}\left(d_{3}\right)-P_{2}\left(d_{3}\right)+P_{2}\left(d_{3}+d_{2}\right) \\
& -P_{1}\left(d_{3}+d_{2}\right)+P_{1}\left(d_{1}+d_{2}+d_{3}\right)
\end{aligned}
$$

\section{EXPERIMENTAL RESULTS}

Measurements have been conducted in a semi-anechoic environment using a Rhode \& Schwartz Vector Network Analyzer (VNA), with 101 equally spaced frequency points spanning from 55 to $65 \mathrm{GHz}$. The IF bandwidth has been set to $10 \mathrm{~Hz}$ and the transmitter power to $0 \mathrm{dBm}$. Time gating has been used in order to remove multipath effects. The cutoff time delay was set to $0.16 \mathrm{~ns}$ plus the expected delay of the main propagation path. A photograph of the measurement set-up is provided in Fig. 3.

The propagation surface is a flat body phantom whose electric properties have been presented in [17]. In order to measure the field strength over the propagation surface, openended vertically-polarized WR-15 waveguides without flanges are used as transmitting and receiving antennas. The receiving waveguide is mounted on a digitally-controlled positioner with a $0.05 \mathrm{~mm}$-resolution. The path loss has been measured over a distance between the transmitting and receiving waveguides ranging from 5 to $50 \mathrm{~cm}$. The waveguide apertures are located about $3 \mathrm{~mm}$ above the surface $(h=z=3 \mathrm{~mm}$, in Fig. 1). Norton's formulations validity for determining propagation over a flat surface using open waveguides has been proven [5], which allows comparing measurement results with the analytical model of section II.

Seven measurement scenarios have been considered, as summarized in Table I; they are based on different combinations of metallic/phantom segments. Metallic inserts have been used in practice for metallic regions; the strip width is fixed $(5 \mathrm{~cm})$, whereas their lengths vary, as reported in Table I. Further transmission measurements have shown that wider strip widths do not lead to significant changes in the results. This can also been theoretically understood by noting that the maximum Fresnel radius is $25 \mathrm{~mm}$ which is actually exactly like the strip width (one needs to take into account twice the radius). This simply means that the Fresnel ellipsoid is filled up by all the metallic width which allows us to neglect the edge effects and to assume a 1-D geometry. Scenario 0 is defined as the reference one since it corresponds to propagation over a homogeneous flat human skin. The corresponding measured and analytical results are shown in Fig. 4; the measured path loss at a distance of $5 \mathrm{~cm}$ between the transmitter and receiver is in the range of values obtained in [5] (between -34 and $40 \mathrm{~dB}$ attenuation).

Each analytical curve has been normalized with respect to the first measurement. Fig. 4(a) and 4(b) present path loss with respect to the distance $\rho$ when inserting a metallic surface between the transmitter and receiver for the different scenarios summarized in Table I. The slope change in the path loss decay is clearly visible at $\rho$ values for which the propagation is on the metallic surface. It is clearly shown that this results in a decrease of the overall path loss. The experimental results are in very good agreement with the analytical model and demonstrate that adding a metallic insert allows improving

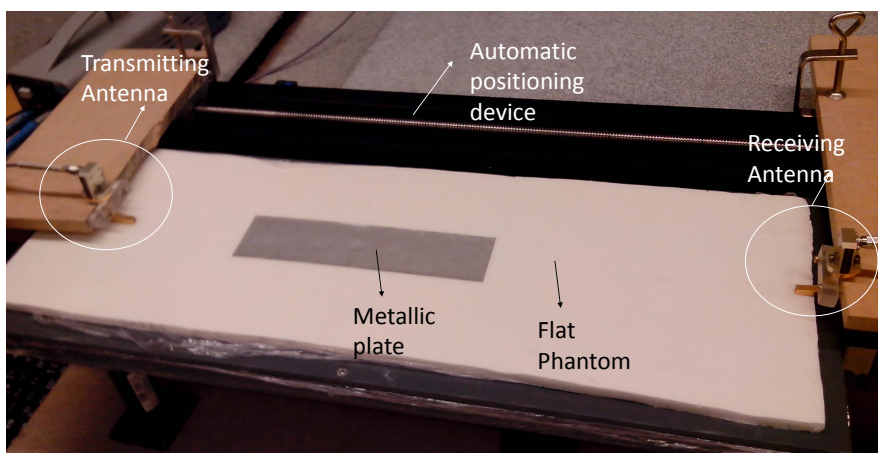

Fig. 3. Photo of the experimental set-up.

TABLE I

MEASUREMENT SET-UPS

\begin{tabular}{c|ccc}
\hline \hline \multirow{2}{*}{ Measurement scenario } & \multicolumn{3}{|c}{ set-up } \\
& \multicolumn{3}{|c}{ Skin } \\
\multirow{2}{*}{ Scenario 0 } & \multicolumn{3}{c}{$5 \mathrm{~cm}$} \\
& Skin & Metal & Skin \\
& $10 \mathrm{~cm}$ & $10 \mathrm{~cm}$ & $30 \mathrm{~cm}$ \\
\hline \multirow{2}{*}{ Scenario 1 } & Skin & Metal & Skin \\
& $10 \mathrm{~cm}$ & $20 \mathrm{~cm}$ & $20 \mathrm{~cm}$ \\
\hline \multirow{2}{*}{ Scenario 2 } & Skin & Metal & Skin \\
& $20 \mathrm{~cm}$ & $10 \mathrm{~cm}$ & $20 \mathrm{~cm}$ \\
\hline \multirow{2}{*}{ Scenario 3 } & Metal & Skin & \\
& $10 \mathrm{~cm}$ & $40 \mathrm{~cm}$ & \\
\multirow{2}{*}{ Scenario 4 } & Skin & Metal & \\
& $40 \mathrm{~cm}$ & $10 \mathrm{~cm}$ & \\
\hline \multirow{2}{*}{ Scenario 5 } & Metal & Skin & Metal \\
& $10 \mathrm{~cm}$ & $30 \mathrm{~cm}$ & $10 \mathrm{~cm}$ \\
\hline \multirow{2}{*}{ Scenario 6 }
\end{tabular}

the propagation over the body. This model leads to the results achieved by [10] which showed that covering all the propagation surface with an electro textile increases the link budget. Fig. 4(c) demonstrated the role of the location of the metallic plate under the antennas. It is shown that in this case the gain is higher compared to other scenarios.

Discrepancies between theoretical and experimental results show a maximum absolute error of $2.74 \mathrm{~dB}$ (for scenario 6) and a mean absolute error of $1.33 \mathrm{~dB}$ (for scenario 1). These errors are mainly due to the imperfections of the phantom surface. During the experiments, it has been observed that the antenna was not always at the exactly same height above the surface for different distances. A variation of height of maximum $1 \mathrm{~mm}$ has been observed during the measurement campaign. However, measurements and theory are sufficiently similar to validate the theoretical model.

\section{NUMERICAL STUdy AND Discussion}

The analytical model can be used in order to determine the minimum path loss achievable with scenarios described in Table II and Fig. 1. The objective is to optimize the path loss reduction (gain factor) $G$ with and without the use of a metallic plate. In Section II, we assumed that $z$ and $h$ are equal to $3 \mathrm{~mm}$ to experimentally validate the analytical model. Here we also study the impact of the height of the antennas on $G$. The maximum distance $\rho=d_{1}+d_{2}+d_{3}$ is considered to be 


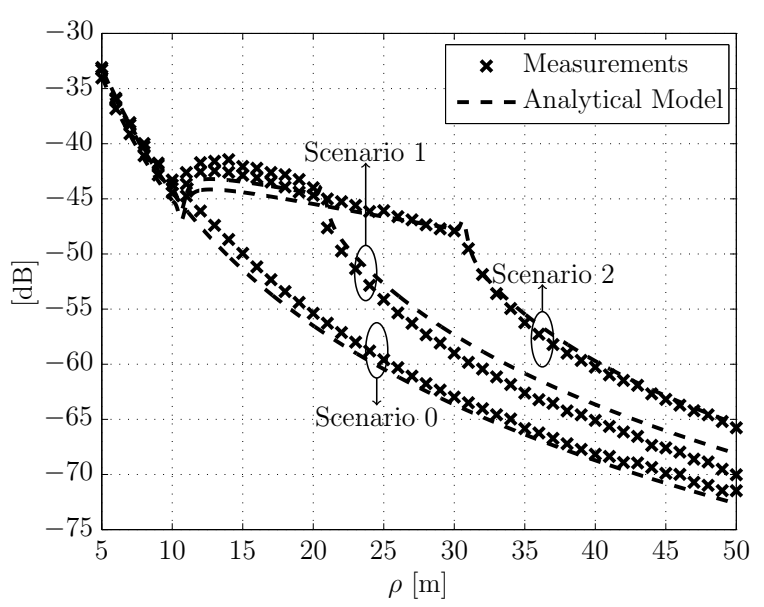

(a) Scenarios 1 and 2

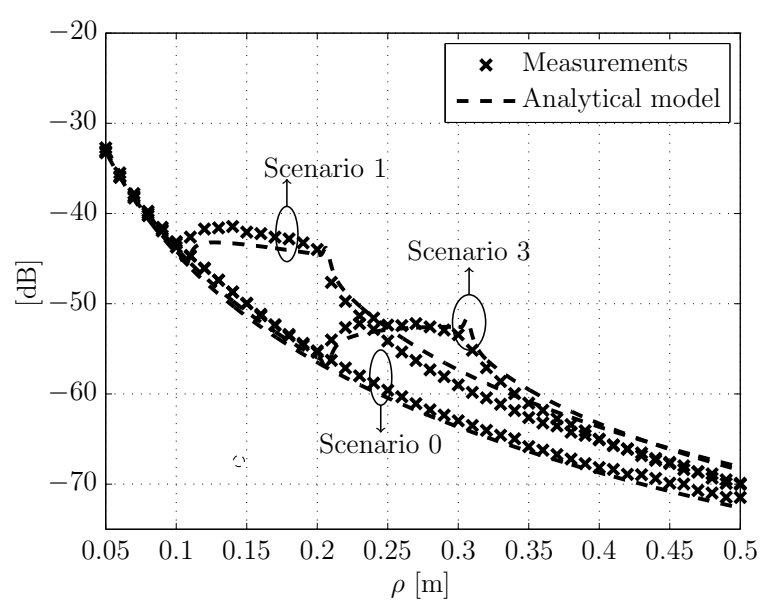

(b) Scenarios 1 and 3

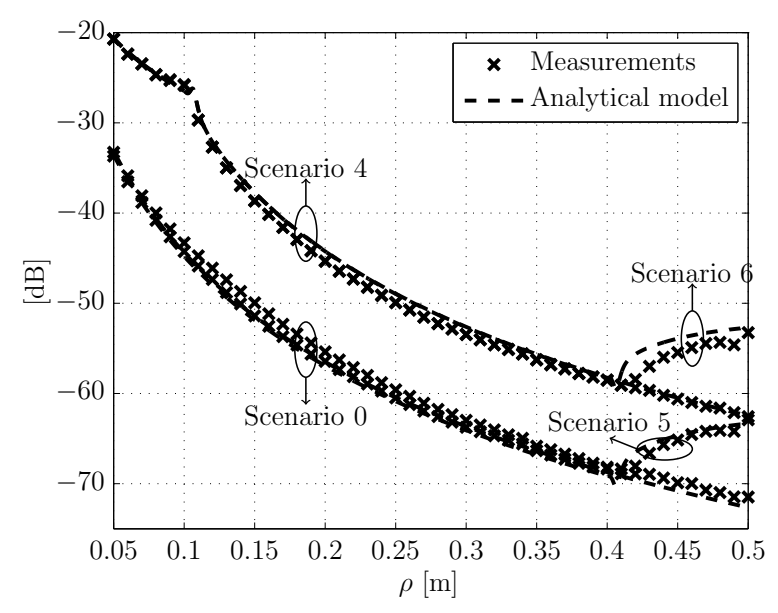

(c) Scenarios 4, 5 and 6

Fig. 4. Measured and simulated path gains for the different scenarios. Dotted curves refer to transmission coefficients computed using Norton's or Millington formulations assuming the transmitting and receiving antennas are placed $3 \mathrm{~mm}$ above the phantom. Curves with markers correspond to measurements.

$50 \mathrm{~cm}$ which is a typical link length that can occur in BAN
TABLE II

MEDIUM PER REGION FOR THE TWO DIFFERENT SCHEMES

\begin{tabular}{cccc}
\hline \hline Scheme & Region 1 & Region 2 & Region 3 \\
\hline 1 & Skin & Metal & Skin \\
2 & Metal & Skin & Metal \\
\hline \hline
\end{tabular}

[1]. Hence, the gain factor $G$ will be defined as:

$$
G=P^{\text {With metal }}(\rho=0.5 \mathrm{~m})-P^{\text {Only Skin }}(\rho=0.5 \mathrm{~m}) .
$$

\section{A. Considered Schemes}

The first scenario studies the effect of a metallic plate placed between the two antennas. It is called "Skin-MetalSkin". This scenario is interesting in the field of topology studies and relay device location in BAN [18]. The idea is to replace complex relay devices made up receiver and transmitter by a simple metallic plate if the achieved gain is sufficient.

The second scenario analyses the propagation when the transmitting and receiving antennas are placed above a metallic plate. It is called "Metal-Skin-Metal". This scheme allows to analytically study the gain factor obtained with the size of the ground plane placed under the antenna. Millington formula here allows one to tackle this problem from the propagation point of view.

\section{B. Scheme 1: Skin-Metal-Skin}

Scheme 1 studies the influence of a metallic inserts between the transmitter and receiver placed on the human body. This metallic insert acts as a "repeater", having a gain factor proportional to its length (Fig. 4(a) and 4(b)). The gain factor $G$ is proportional to the length of metal. In the following, only the sizes $d_{1}$ and $d_{2}$ of the skin region and the length of the metallic region are discussed.

Fig. 5 shows that the gain factor value $G$ increases with the length of the metallic plate as expected. Also $G$ increases by placing the transmitter closer to the metallic insert. By reciprocity, the same curves as in Fig. 5 can be obtained by replacing $d_{1}$ by $d_{3}$. These results only suggest that the gain factor is higher when approaching the antennas to the insert, and this scenario will be consequently further investigated in the next section (scheme 2).

Fig. 6 demonstrates the impact of $h$ and $z$ on the gain factor $G$. The metallic plate is placed between the two antennas so that $d_{1}=d_{3}=0.25-d_{2} / 2$. This situation is not optimal as can be seen in Fig. 6 but allows us to analyze the impact of modifying the parameter $d_{2}$ only. These curves show that $G$ is higher when antennas are closer to the surface. Since the path loss is higher close to the surface, adding a metallic surface shows a stronger effect and save more of the otherwise dissipated power in the surface in this latter case. This suggests that the recovery effect applies to the surface wave component and not on the space wave components (components defined in [5]). 


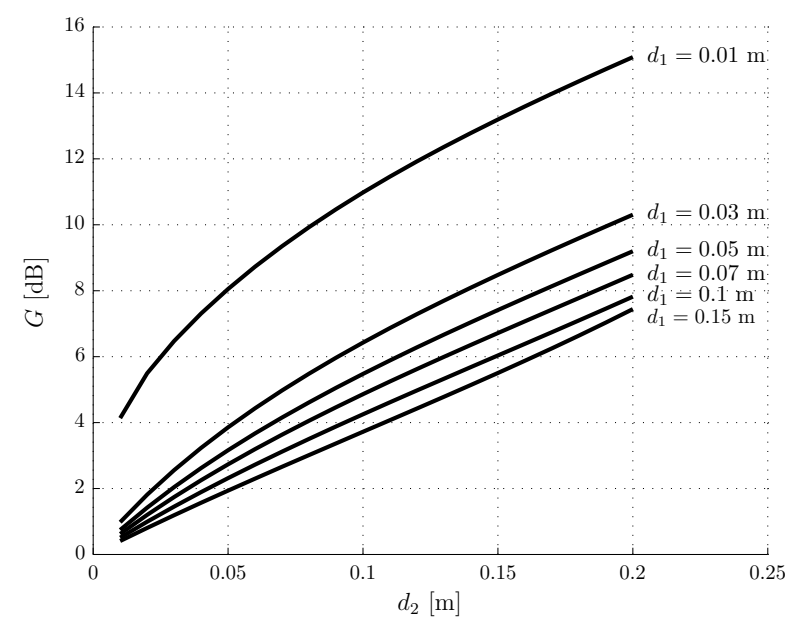

Fig. 5. Scheme 1. Computed gain factor values $G$ obtained by adding a metallic plate of length $d_{2}$ with $h=z=3 \mathrm{~mm}$, for various values of $d_{1}$ (distance between the transmitting antenna and metallic plate).

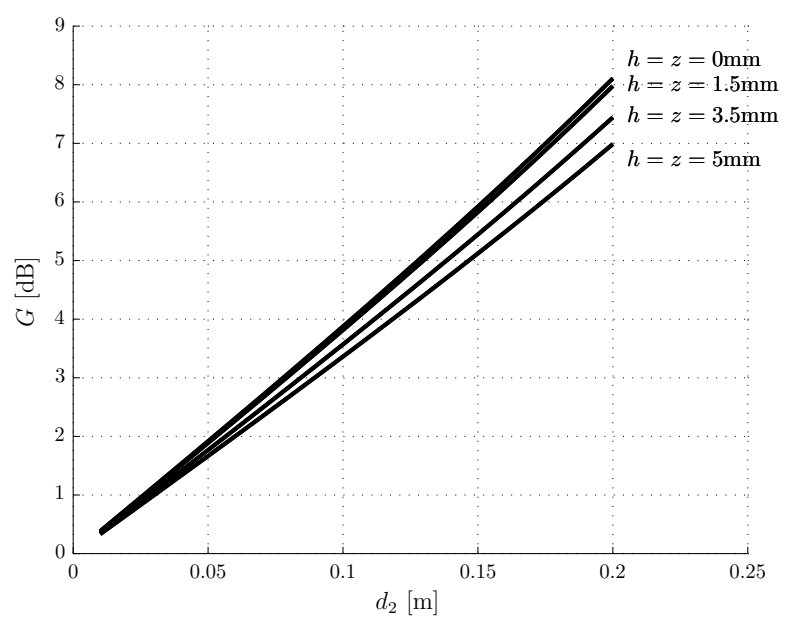

Fig. 6. Scheme 1. Computed gain factor values $G$ obtained by adding a metallic plate of length $d_{2}$ for various values of $h=z$.

\section{Scheme 2: Metal-Skin-Metal}

Scheme 2 studies the influence of a metallic insert placed under the transmitter and the receiver worn on the human body. As shown in Fig. 4(c), the metallic plates under the antennas results in the increase of the link budget. In the following, the gain factor $G$ is evaluated considering $d_{1}+d_{2}+d_{3}=0.5 \mathrm{~m}$. Let us define the total length of metal as $d_{\text {metal }}=d_{1}+d_{3}$, the coefficients $\alpha_{1}$ and $\alpha_{3}$ are defined as follows $\alpha_{1}=d_{1} / d_{\text {metal }}$ and $\alpha_{3}=d_{3} / d_{\text {metal }}=1-\alpha_{1}$.

Fig. 7 presents the variation of $G$ with $d_{\text {metal }}$. Using equal values for $\alpha_{1}=\alpha_{3}=0.5$ leads to the best performance. In [19], the effect of a circular groundplane is studied. It is shown that increasing the groundplane size decreases the currents in the propagation surface and reduces the energy transmitted inside the surface. This leads to a better link budget as suggested by the results presented here. The radiation

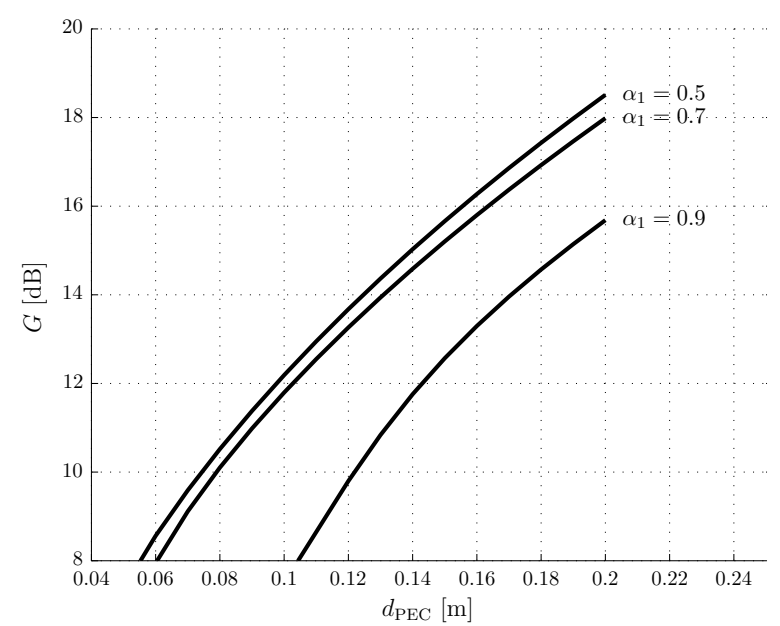

Fig. 7. Scheme 2. Computed gain factor values $G$ obtained by adding a metallic plate of length $d_{\text {metal }}$ with $h=z=3 \mathrm{~mm}$, for various values of $\alpha_{1}$ (metal length repartition between transmitter and receiver side).

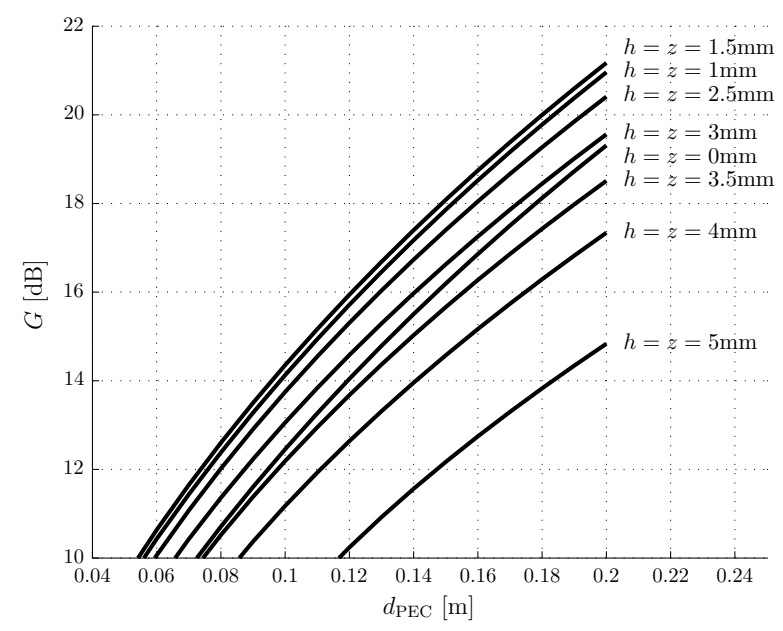

Fig. 8. Scheme 2. Computed gain factor values $G$ obtained by adding a metallic plate of length $d_{\text {metal }}$ with $\alpha_{1}=0.5$ for various values of $h=z$.

patterns presented in [19] show that more power is dissipated in the surface closer to the antennas. In conclusion, the metallic surface increases the link budget and by reciprocity, it can be noted that swapping $\alpha_{1}$ and $\alpha_{3}$ gives the same results.

Fig. 8 presents the gain factor for different values of the antenna heights $h$ and $z$ with a coefficient $\alpha_{1}=0.5$ which is the optimal value. The results are not as straightforward as in Fig. 6. Two different effects contribute to the modification of the path loss. When $h$ varies, the radiation pattern of the antenna does change as well, thereby leading to an increase or a decrease of the gain toward the Rx direction. In addition, as $h$ increases, the shielding effect of the ground plane becomes less effective and more energy is lost inside the skin. These considerations are similar to the ones discussed in [20]. 


\section{Discussion}

Fig. 7 shows that by increasing the length of the metal plates under the antennas, the budget link increases. It can be inferred that metal plates reduce the surface losses. However, since the path loss has a logarithmic decay, the surface losses are not uniform along the propagation path and hence, similar lengths of metal plates (as shown in Fig. 5) give different gain factors with respect to their position. The best link budget is therefore achieved with scheme 2 for a same total length of metal. It is shown that the use of a $3.5-\mathrm{cm}$ metallic plate in front of each antenna allows improvement of the power budget by $10 \mathrm{~dB}$. This seems to be a high constraint. However, in Section 3 , a metallic adhesive paper has been used and it showed great performance. The malleability of such matter makes it practical for body-centric communications. Also, scheme 1 increases the link budget of about 5 to $10 \mathrm{~dB}$ by using a metallic surface between the two antennas. This can be useful for replacing relays and saving power with a passive structure. In total, using the two presented schemes and multiple electro textile surfaces may accommodate saving up to $30 \mathrm{~dB}$ without the need of any active equipment.

\section{CONCLUSION}

Millington's equations are proposed to model propagation over mixed paths in the scope of wireless Body Area Networks. The mixed paths include human skin and metallic surfaces. Millington's formulation allows one to address the problem of discontinuities between these two materials. In complement to Millington's equations, Norton's solutions have been used in order to solve the propagation above flat surface.

It has been quantitatively shown that using longer metallic insert increases the path loss reduction and therefore, increases the link budget. Placing a metallic surface between the two antennas allows one to save between about 1 and $10 \mathrm{~dB}$ depending on the length of the surface. However, placing the metallic plate under the antennas allows saving up to $20 \mathrm{~dB}$ for the same size of the surface. This technique can easily be implemented for passive relaying of power. The path loss improvement has been presented for an ideal flat body geometry. Accounting for the effects of body curvature and body movements is beyond the scope of this letter.

\section{ACKNOWLEDGMENT}

This work was performed within the Labex SMART supported by French state funds managed by the ANR within the Investissements d'Avenir programme under reference ANR11-IDEX-0004-02. This work is also supported by grants of the FNRS (FRIA grant), Belgium.

\section{REFERENCES}

[1] S. L. Cotton, R. D’Errico, and C. Oestges, "A review of radio channel models for body centric communications," Radio Science, vol. 49, pp. 371-388, 2014.

[2] P. S. Hall and Y. Hao, Antennas and Propagation for Body-Centric Wireless Networks, Norwood, MA 2006.

[3] N. Chahat, M. Zhadobov, and R. Sauleau, "Antennas for body centric wireless communications at millimeter wave frequencies," In Progress in Compact Antennas, InTech, pp. 23-55, Sep. 2014.
[4] A. Pellegrini, A. Brizzi, L. Zhang, K. Ali, Y. Hao, X. Wu, C. Constantinou, Y. Nechayev, P. Hall, N. Chahat, M. Zhadobov, and R. Sauleau, "Antennas and propagation for body-centric wireless communications at millimeter-wave frequencies: A review," IEEE Antennas Propag. Mag., vol. 55, no. 4, pp. 262-287, Aug. 2013.

[5] N. Chahat, G. Valerio, M. Zhadobov, and R. Sauleau, "On-body propagation at $60 \mathrm{GHz}$," IEEE Trans. Antennas Propag., vol. 61, no. 4, pp. 1876-1888, Apr. 2013

[6] T. Mavridis, L. Petrillo, J. Sarrazin, D. Lautru, A. Benlarbi-Delaï, and P. De Doncker, "Creeping wave model of diffraction of an obliquely incident plane wave by a circular cylinder at $60 \mathrm{GHz}$," IEEE Trans. Antennas Propag., p. 1, 2014.

[7] A. Guraliuc, M. Zhadobov, G. Valerio, N. Chahat, and R. Sauleau, "Effect of textile on the propagation along the body at $60 \mathrm{GHz}$," IEEE Trans. Antennas Propag., vol. 62, no. 3, pp. 1489-1494, Mar. 2014.

[8] L. Petrillo, T. Mavridis, J. Sarrazin, A. Benlarbi-Delai, and P. De Doncker, "Statistical on-body measurement results at $60 \mathrm{GHz}$," IEEE Trans. Antennas Propag., vol. 63, no. 1, pp. 400-403, Jan. 2015.

[9] Y. I. Nechayev, X. Wu, C. C. Constantinou, and P. S. Hall, "Millimetrewave path-loss variability between two body-mounted monopole antennas," IET Microw., Antennas Propag., vol. 7, no. 1, pp. 1-7, Jan. 2013.

[10] A. Guraliuc, M. Zhadobov, G. Valerio, and R. Sauleau, "Enhancement of on-body propagation at $60 \mathrm{ghz}$ using electro textiles," IEEE Antennas Wireless Propag. Lett., vol. 13, pp. 603-606, 2014.

[11] R. W. P. King, G. J. Fikioris, and R. B. Mack, Cylindrical antennas and arrays. Cambridge University Press, 2002.

[12] G. Millington, "Ground-wave propagation over an inhomogeneous smooth earth," Proceedings IEE Part IV, vol. 96, no. 39, pp. 53-64, Jan. 1949.

[13] C. Bourlier and G. Kubicke, "Ground wave propagation along an inhomogeneous rough surface in the hf band: Millington effect for a flat earth," IEEE Trans. Geosci. Remote Sens., vol. 49, no. 4, pp. 13741382, Apr. 2011.

[14] L. Petrillo, T. Mavridis, J. Sarrazin, D. Lautru, A. Benlarbi-Delai, and P. De Doncker, "Analytical creeping wave model and measurements for $60 \mathrm{GHz}$ body area networks," IEEE Trans. Antennas Propag., vol. 62, no. 8, pp. 4352-4356, Aug. 2014.

[15] P. A. Hasgall, E. Neufeld, M.-C. Gosselin, A. Klingenböck, and N. Kuster, "IT'IS database for thermal and electromagnetic parameters of biological tissues, version 2.2," July 11th, 2012. [Online]. Available: http://www.itis.ethz.ch/database

[16] Recommendation, ITUR, 368-6, Ground-wave propagation curves for frequencies between $10 \mathrm{kHz}$ and $30 \mathrm{MHz}$, International Telecommunication Union, Radiocommunications Section, 2005.

[17] N. Chahat, M. Zhadobov, and R. Sauleau, "Broadband tissue-equivalent phantom for ban applications at millimeter waves," IEEE Microw. Theory Tech., vol. 60, no. 7, pp. 2259-2266, Jul. 2012.

[18] J.-M. Dricot, S. Van Roy, G. Ferrari, F. Horlin, and P. De Doncker, "Impact of the environment and the topology on the performance of hierarchical body area networks," EURASIP J. Wireless Commun. Netw., vol. 2011, no. 1, pp. 1-17, 2011.

[19] A. Leitner and R. Spence, "Effect of a circular groundplane on antenna radiation," Journal of Applied Physics, vol. 21, no. 10, pp. 1001-1006, Oct. 1950.

[20] Y. Nechayev, C. Constantinou, X. Wu, and P. Hall, "De-polarization of on-body channels and polarization diversity at $60 \mathrm{GHz}$," Antennas and Propagation, IEEE Transactions on, vol. 62, no. 12, pp. 6519-6523, 2014. 